\title{
The goldilocks effect: the rhythms and pace of hospital life
}

\author{
Jeffrey Braithwaite* ${ }^{*}$, Louise A. Ellis, Kate Churruca and Janet C. Long
}

\begin{abstract}
Background: While we have made gains in understanding cultures in hospitals and their effects on outcomes of care, little work has investigated how the pace of work in hospitals is associated with staff satisfaction and patient outcomes. In an era of efficiency, as speed accelerates, this requires examination.

Discussion: Older studies of pace in cities found that faster lifestyles were linked to increased coronary heart disease and smoking rates, yet better subjective well-being. In this debate we propose the Goldilocks hypothesis: acute care workplaces operating at slow speeds are associated with factors such as increased wait lists, poor performance and costly care; those that are too fast risk staff exhaustion, burnout, missed care and patient dissatisfaction. We hypothesise that hospitals are best positioned by being in the Goldilocks zone, the sweet spot of optimal pace.
\end{abstract}

Conclusion: Testing this hypothesis requires a careful study of hospitals, comparing their pace in wards and departments with measures of performance and patient outcomes.

Keywords: Pace of life, Busy-ness, Staff satisfaction, Patient outcomes, Efficiency, Optimal hospital performance, Complexity

\section{Background}

Hospitals are fast-moving workplaces characterized by the brisk walk of staff in corridors, quick turnover of patients in wards and the rapid response of emergency teams. We notice no one has studied this aspect of hospital culture.

In the 1970s, psychology researchers began observing the speed at which pedestrians walk and carry out everyday tasks, uncovering significant differences in the rapidity of life between cities and countries [1,2]. Arguing that such momentum plays a central role in defining the personality of a setting, Levine and Norenzayan showed how pace of life is intertwined with the social-psychological and community characteristics of the cities they observed [3]. In this study, Bern, Zurich, Dublin and Frankfurt were fastest; New York, Singapore and Toronto were next; and Rio de Janeiro, Jakarta and Mexico City were slowest. Later, Levine proposed that the level of "busy-ness-the summation of both speed and activity" [4] was a window into the inhabitants' culture.

\footnotetext{
* Correspondence: jeffrey.braithwaite@mq.edu.au

Centre for Healthcare Resilience and Implementation Science, Australian Institute of Health Innovation, Macquarie University, Level 6, 75 Talavera Road, North Ryde, NSW 2109, Australia
}

Much like cities, every organisation has a uniquely patterned culture. A good culture, one that is productive, collegiate and supportive, is related to positive patient and organisational outcomes [5]. But busy-ness and the pace of hospital organisational life have not been measured (see Table 1, Glossary of terms). We propose that the tempo of staff is an important variable in hospital culture, and ultimately, in performance, that can be objectively measured.

\section{Factors contributing to the unique personality of a hospital}

Many factors influencing the speed of hospitals are generic. These factors are mostly linked to the context and nature of the tasks being performed, and the modern drive for efficiency [3, 6-8]. Different units have different activity patterns, however $[9,10]$. In Emergency Departments, for example, the pace is two-speed: in downtime, and when there is a rush of patients-a kind of choreographed efficiency. On the more predictable rehabilitation wards, the daily routine is more or less measured and orderly. In palliative care, on the other hand, there is a slower, gentler, and more respectful pace [11]. Theatres have a distinguishable tempo: anesthetized patients lie motionless while surgeons hover above them, then all is speed and 
Table 1 Glossary of terms

\begin{tabular}{|c|c|}
\hline Concept & Definition \\
\hline Busy-ness (of hospital organisation life) & $\begin{array}{l}\text { For Levine (2005), busy-ness was a state of or subjective experience of having a lot to do, and perceiving } \\
\text { that you don't have much time for other activities beyond your current work, with two components: } \\
\text { speed and activity. When you are busy, you perceive that you are not available to complete much else, } \\
\text { and that you need to work or concentrate on a task or tasks. }\end{array}$ \\
\hline Pace (of hospital organisation life) & $\begin{array}{l}\text { The rate of at which clinical and non-clinical work is being progressed; the psychological or subjective } \\
\text { experience of rapidity of work, and density of perceptions of this. }\end{array}$ \\
\hline $\begin{array}{l}\text { Speed of hospitals (also referred } \\
\text { to as the tempo of hospitals) }\end{array}$ & $\begin{array}{l}\text { The relative rapidity of staff movement, and rate of activities being done e.g., walking pace between } \\
\text { wards, time available to do a drug round; or as a global measure of staff activities. }\end{array}$ \\
\hline Briskness & Staff quickness; their liveliness and vigour. \\
\hline Step up or stepping up the pace & The act of increasing speed or pace: a feeling of accelerating busy-ness. \\
\hline Four-hour rule in Emergency Departments & $\begin{array}{l}\text { Based on the UK experience, Australia introduced the National Emergency Access Target (NEAT) in } 2011 . \\
\text { This states that patients should be admitted, discharged or transferred within } 4 \text { h of arrival, in Emergency } \\
\text { Departments (Ngo, H. et al. 2018; Sullivan, C. et al. 2014). }\end{array}$ \\
\hline $\begin{array}{l}\text { ETTO principle (efficiency-thoroughness } \\
\text { trade-off) }\end{array}$ & $\begin{array}{l}\text { This principle, expounded by Hollnagel (2009), suggests that people must make a trade-off between } \\
\text { the resources of preparing an activity and the resources in completing that activity. This could be a } \\
\text { trade-off of thoroughness over efficiency, or efficiency over thoroughness. Thoroughness and efficiency } \\
\text { cannot be maximised at the same time. }\end{array}$ \\
\hline
\end{tabular}

activity as drapes and gowns are pulled off, doors thrown open and trolleys reshuffled, ready for the next procedure.

But, like the research on cities, there are grounds for believing that each hospital has a distinctive personality, reflecting "what is valued, the dominant managerial and leadership styles, the language and symbols, the procedures and routines, and the definitions of success that make a hospital unique" [12]. Levine and Norenzayan, for example, found that economically more productive cities in cooler climates, with more individualistic cultures, and higher levels of well-being, had a brisker pace of life. Perhaps, consistency in pace in hospitals might reflect not only such facets as the stability of the culture, but also the professionalism of the clinical workforce, and financial performance of the organisation.

\section{Increasing pressures on hospitals to step up}

Is a faster speed, representing productivity and performance, always a good thing? Levine and Norenzayan indicated that the inhabitants of briskly-paced cities were economically better off and enjoyed subjectively better levels of well-being, but had higher smoking rates, and were associated with increased morbidity due to coronary heart disease [3]. Faced with ever-increasing cost constraints as well as demands for services, hospitals have experienced accelerating pressures to step up the pace $[6,13]$. For example, time-based targets, such as the rule in Emergency Departments in the United Kingdom and Australia that people need to be seen within four hours [14, 15] and throughput pressures exemplified by elective surgery wait lists $[16,17]$ are pushing staff to fit more and more tasks into a set amount of time. Work is expanding in other ways too, such as with the introduction of burdensome documentation, rules and regulations [18]. By stepping up the pace, hospitals may be compromising their delivery of high quality patient care [19]. Indeed, we know that patient satisfaction is lower when nurses and patients feel too rushed [20], while quality of care has been linked to how much time hospital staff spend with patients [20-22]. In the complexity of performance, Hollnagel refers to this as the ETTO-the Efficiency-Thoroughness Trade-Off [23].

Exacerbating this, burnout rates among doctors are reportedly rising, and reaching epidemic levels [24]. Stress and fatigue highlight the problem of hospitals with too few resources and too many demands, which may cause staff to extend their pace beyond that which is sustainable.

Perhaps there is an optimal pace for hospitals to function well: too fast and mistakes are made, staff leave exhausted and burnt out, and patients are dissatisfied with their care; but too slow and things do not get done at day's end, boredom settles in, expenses escalate, and wait lists blow out. Thus, the underlying theory is that pace is related to performance, as depicted in Fig. 1. Based on the Yerkes-Dodson law of the relationship between arousal and performance [25], we suggest that the cultural sweet spot is the Goldilocks zone of the inverted-U function of briskness, where external demand and internal motivations, and the tension between efficiency and quality, are in equilibrium (Fig. 2).

In recognition of the concavity of the curve, we can therefore model performance in hospitals as a quadratic function of the pace.

$$
\sigma=\mathrm{f}(\mathrm{P})=\mathrm{aP}^{2}+\mathrm{bP}+\mathrm{C}
$$

where: $\sigma=$ performance; $\mathrm{P}=$ pace, and $\mathrm{a}, \mathrm{b}, \mathrm{c}=$ coefficients to be determined.

We assume that: 


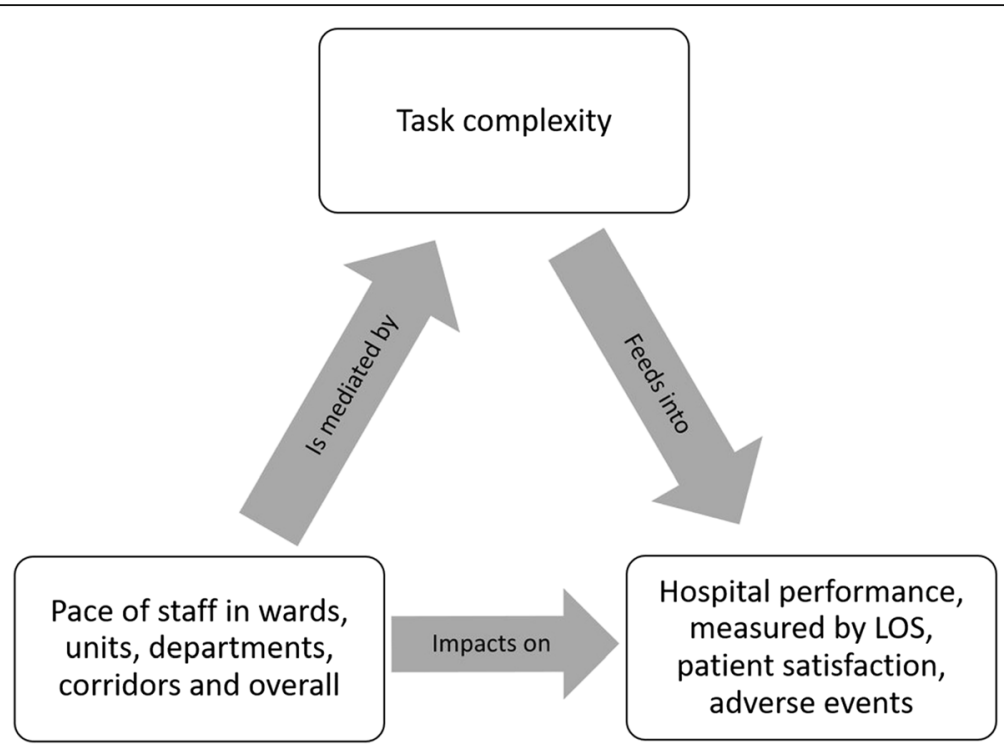

Fig. 1 Underlying theoretical model

- The pace of hospital life is related to hospital performance, measured by length of stay, and other efficacy measurements.

- When pace is at its minimum or maximum, performance is at minimum.

- Performance is best under conditions of intermediate pace

Supporting our hypothesis, research applying the Yerkes-Dodson law found that different tasks require different levels of arousal for optimal performance [25, 26]. Specifically, the law holds that easier tasks require higher levels of arousal (e.g., faster pace) for optimal performance than more difficult tasks. So in accordance with such previous research, we propose that the optimum level of pace is likely to be lower for more complex, unfamiliar or difficult tasks, and higher for simple or familiar tasks requiring endurance and persistence. This can be graphed as a 3-D performance surface (Fig. 3).

\section{Getting to the goldilocks zone}

Despite hospital tempo receiving no substantial attention to date, there is much to study here. Differences in the cultural characteristics of workplaces may be expressed in different paces of hospital life and distinctive organisational personalities. For example, the particular way that nurses routinely communicate with each other at change of shift-structured,

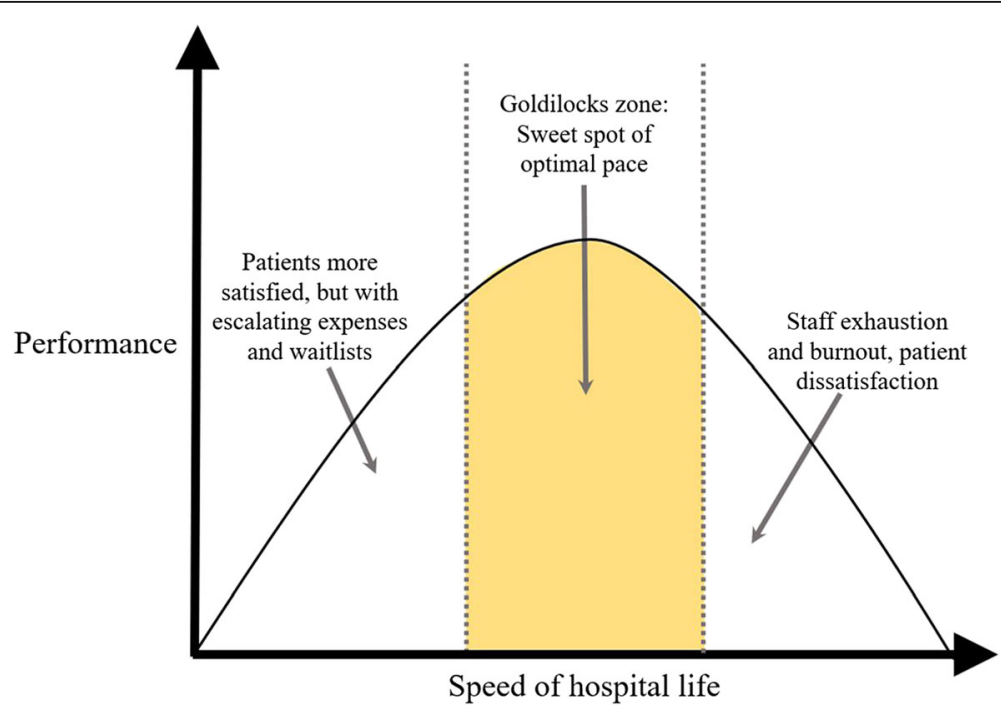

Fig. 2 The pace normal distribution curve 
Efficiency Surface (pace, complexity)

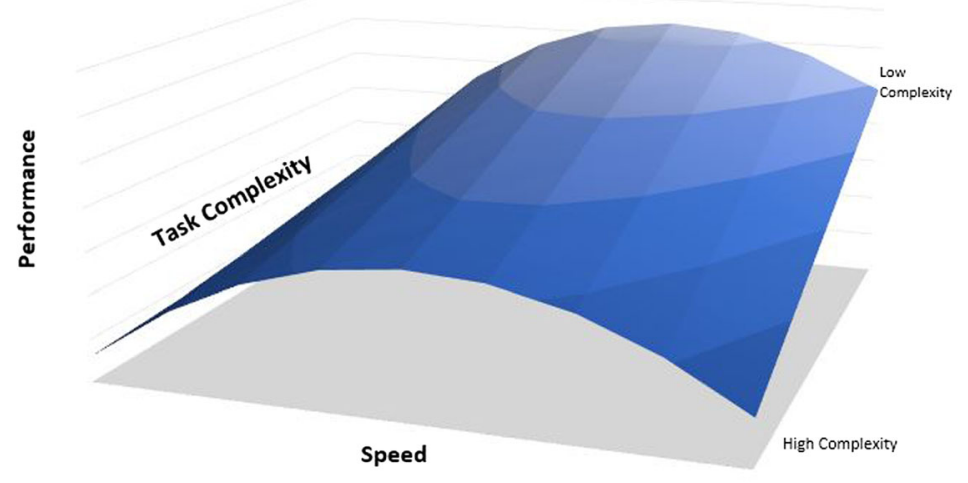

Fig. 3 3D surface plot of performance, complexity and speed

comprehensive and open, or ad hoc, shallow and defensivedetermines at what speed handover of patients should proceed [9]. Tempo can also reflect the local organisational pecking order, in which the most powerful player sets the agenda and the less powerful must accommodate their speed to suit (e.g., theatre staff made to wait for a tardy surgeon). There may, too, be mismatches in cultural expectations ("I'm on time, why aren't you?") [27].

If speed is something perpetuated and normalised in the culture of an organisation through the staff routines [9], as well as reflecting something about the organisation's collective personality and context, then this suggests that through conscious and concerted effort, pace is amenable to change. So, we submit that efforts to decrease a pace that has become uncomfortably or dangerously fast, or stepping up the tempo of an inefficiently slow one, should spring from a collective recognition that speed can affect quality of care, staff well-being, and hospital performance.

\section{Conclusion}

Just like Goldilocks' porridge, not too hot, not too cold, but just right seems to be the sweet spot. This is a hypothesis worth postulating. We'll only know if we put the argument to an empirical test. That will involve a carefully designed study of multiple hospitals, comparing their rhythm and pace in wards, corridors, emergency departments and specialised units, and hospital-wide, with measures of their performance. That's the next step.

\section{Funding}

JB is Professor of Health Systems Research and Founding Director of the Australian Institute of Health Innovation at Macquarie University, Sydney, Australia. This work was supported by the Australian Institute of Health Innovation which receives $80 \%$ of its core funding from category one, peer-reviewed grants, chiefly, the National Health and Medical Research Council (NHMRC) and Australian Research Council (ARC) funding which includes, most recently, the NHMRC Partnership Grant for Health Systems Sustainability (ID: 9100002).
Authors' contributions

$J B$ led the project, conceived the manuscript and wrote various parts of it. $J B, K C, J C L$ and LAE drafted parts of the manuscript and read, approved and edited the final version of the manuscript.

Ethics approval and consent to participate

Not applicable.

\section{Consent for publication}

Not applicable.

Competing interests

The authors declare that they have no competing interests.

\section{Publisher's Note}

Springer Nature remains neutral with regard to jurisdictional claims in published maps and institutional affiliations.

Received: 23 April 2018 Accepted: 2 July 2018

Published online: 06 July 2018

\section{References}

1. Bornstein M. The pace of life: revisited. Int J Psychol. 1979;14(1-4):83-90.

2. Milgram S. The experience of living in cities. Science. 1970;167(3924):1461-8.

3. Levine RV, Norenzayan A. The pace of life in 31 countries. J Cross-Cult Psychol. 1999;30(2):178-205.

4. Levine R. A geography of busyness. Soc Res. 2005;72(2):355-70.

5. Braithwaite J, Herkes J, Ludlow K, Testa L, Lamprell G. Association between organisational and workplace cultures, and patient outcomes: systematic review. BMJ Open. 2017;7:e017708.

6. Kc D, Terwiesch C. Impact of workload on service time and patient aafety: an econometric analysis of hospital operations. Manag Sci. 2009;55(9):1486-98.

7. Barrett AK. Breaking boundaries: temporality and work-life pactices in hospital organizations. West J Commun. 2014;78(4):441-61.

8. Klitzman R. "Patient-time," "doctor-time," and "institution-time": perceptions and definitions of time among doctors who become patients. Patient Educ Couns. 2007;66(2):147-55.

9. Ballard DI, Seibold DR. Communicating and organizing in time: a meso-level model of organizational temporality. Manag Commun Q. 2003;16(3):380-415.

10. Barrett AK. Breaking boundaries: temporality and work-life practices in hospital organizations. J Commun. 2014;78(4):441-61.

11. Bodtke S, Hospice LK. Hospice and palliative medicine handbook: A clinical guide. 1st ed: CreateSpace; 2016.

12. Siourouni $E$, Kastanioti C, Tziallas D, Niakas D. Healthcare provider's organizational culture: A literature review. Health Sci J. 2012;6(2):212-33.

13. Michael C, Jane G, Mary D, Julie C, Tarnya H, Sarah E, et al. Systems and people under pressure: the discharge process in an acute hospital. J Clin Nurs. 2009;18(4):549-58. 
14. Ngo H, Forero R, Mountain D, Fatovich D, Man WN, Sprivulis P, et al. Impact of the four-hour rule in western Australian hospitals: trend analysis of a large record linkage study 2002-2013. PLoS One. 2018;13(3):e0193902.

15. Sullivan CM, Staib A, Flores J, Aggarwal L, Scanlon A, Martin JH, et al. Aiming to be NEAT: safely improving and sustaining access to emergency care in a tertiary referral hospital. Aust Health Rev. 2014;38(5):564-74.

16. Siciliani L, Hurst J. Tackling excessive waiting times for elective surgery: a comparative analysis of policies in 12 OECD countries. Health Policy. 2005; 72(2):201-15.

17. Curtis A, Russell C, Stoelwinder J, McNeil J. Waiting lists and elective surgery: ordering the queue. Med J Aust. 2010;192(4):217-20.

18. Braithwaite J, Churruca K, Ellis LA. Can we fix the uber-complexities of healthcare? J R Soc Med. 2017:110(10):392-4.

19. Nugus $P$, Braithwaite J. The dynamic interaction of quality and efficiency in the emergency department: squaring the circle? Soc Sci Med. 2010;70(4):511-7.

20. Teng $\mathrm{Cl}$, Hsiao FJ, Chou TA. Nurse-perceived time pressure and patientperceived care quality. J Nurs Manag. 2010;18(3):275-84.

21. Anand KS, Paç MF, Veeraraghavan S. Quality-speed conundrum: trade-offs in customer-intensive services. Manag Sci. 2010;57(1):40-56.

22. Tsiga E, Panagopoulou E, Sevdalis N, Montgomery A, Benos A. The influence of time pressure on adherence to guidelines in primary care: an experimental study. BMJ Open. 2013;3(4)

23. Hollnagel E. The ETTO principle: efficiency-thoroughness trade-off-why things that go right sometimes go wrong. Farnham. UK: Ashgate; 2009.

24. Lemaire JB, Wallace JE. Burnout among doctors. BMJ. 2017;358:j3360.

25. Yerkes R, Dodson JD. The relation of strength of stimulus to rapidity of habit-formation. J Comp Neurol Psychol. 1908;18(5):459-82.

26. Broadhurst PL. The interaction of task difficulty and motivation: the YerkesDodson law revived. Acta Psychol. 1959;16:321-38.

27. Macduff I. Your pace or mine? Culture, time, and negotiation. Negot J. 2006; 22(1):31-45.

\section{Ready to submit your research? Choose BMC and benefit from:}

- fast, convenient online submission

- thorough peer review by experienced researchers in your field

- rapid publication on acceptance

- support for research data, including large and complex data types

- gold Open Access which fosters wider collaboration and increased citations - maximum visibility for your research: over $100 \mathrm{M}$ website views per year 